УДК 635.9:582.477:631.529.(470.62)

03.00.00 Биологические науки

Biology

ИСПОЛЬЗОВАНИЕ ИНТРОДУЦИРОВАННЫХ
ВИДОВ МОЖЖЕВЕЛЬНИКА С
ПИРАМИДАЛЬНОЙ КРОНОЙ ДЛЯ
ОЗЕЛЕНЕНИЯ В УСЛОВИЯ
КРАСНОДАРСКОГО КРАЯ

Проворченко Ольга Александровна аспирант

Кубанский государственный аграрный

университет, г. Краснодар, Россия

В статье представлены многолетние данные (20072015 гг.) биометрических параметров надземной части растений. Проведена оценка перспективности трех интродуцированных ботанических видов можжевельника и даны рекомендации по их использованию в ландшафтном дизайне. Из 16 изученных сортов можжевельника видов: китайского, обыкновенного и скального установлены весьма перспективные, перспективные и малоперспективные для озеленения в условиях предгорной зоны Краснодарского края

КЛючевые слова: МОЖЖЕВЕЛЬНИК, ИНТРОДУКЦИЯ, ВИД, СОРТИМЕНТ, ПЕРСПЕКТИВА, ДЕКОРАТИВНОСТЬ

\section{USE OF INTRODUCED SPECIES WITH JUNIPER PYRAMIDAL CROWN FOR LANDSCAPING IN THE CONDITIONS OF THE KRASNODAR REGION}

Provorchenko Olga Alexandrovna postgraduate student Kuban State Agrarian University, Krasnodar, Russia

Doi: 10.21515/1990-4665-123-135

The article presents the long-term data (2007-2015.) biometric aboveground plant parts and the estimation of the prospects of the three introduced botanical species of juniper and recommendations for their use in landscape design. We have established very promising, promising and unpromising varieties for landscaping in the conditions of the foothill zone of the Krasnodar region out of 16 varieties of juniper species: China, ordinary and rock

Keywords: JUNIPER, INTRODUCTION, TYPE, ASSORTMENT, PERSPECTIVE, DECORATIVE

Введение. В последние годы у ландшафтных дизайнеров значительно возрос спрос на можжевельники с пирамидальной кроной. Такие интродуцированные виды можжевельника отличаются сохранением декоративности на протяжении всего года, проявляя при этом фитоцидную активность и высокие экологические качества. [1,2,3]

Имеющиеся отечественные питомники декоративных культур, такую потребность в посадочном материале необходимых видов и сортов можжевельников, не обеспечивают не качественно, и тем более по сортовому составу. Заполняют образовавшуюся нишу различные садовые центры, которые завозят широкий сортимент можжевельников из стран Западной Европы (Польша, Италия, Испания, Бельгия, Голландия). Часто такие растения не соответствуют природно-климатическим условиям, где эти растения реализуются. 
Решить данную проблему могут новые отечественные питомники, ориентированные на производстве перспективного посадочного материала для конкретной природно-климатической зоны. [4]

Отсутствие сведений об адаптационных возможностях и биологических особенностях сортов интродуцированных видов можжевельника, сдерживает их распространение в озеленительных насаждениях юга России.

Все выше изложенное и предопределило необходимость проведения данных научных исследований, целью которых была оценка перспектив использования сортов интродуцированных видов можжевельника и рекомендовать лучшие из них для использования в озеленении предгорной зоны Краснодарского края.

Объекты и методы исследований. Исследования проводились в течение 2007-2015гг. в коллекционных насаждениях Крымского селекционного центра «Гавриш» г. Крымска Краснодарского края.

Коллекция 3 видов интродуцированных можжевельников с коллоновидной кроной высажена весной 2007 года на специальном участке со схемой размещения растений 3,0 х 2,0м. Объектами исследований служили 16 сортов. По каждому сорту было высажено по 10 учетных растений (табл. 1).

Учет биометрических параметров роста надземной части растений проводили по общепринятым методикам [5]

Перспективность интродуцентов определяли по модифицированной методике И.А. Смирнова (1989) путем вычисления коэффициента перспективности (Кп) по пяти показателям: зимостойкость $(\mathrm{M})$, засухоустойчивость (3), устойчивость к болезням и вредителям (Б), способность к вегетативному размножению (Р), декоративность (Д) по формуле: [6] 


$$
\text { КП = -------------------- }
$$

\begin{tabular}{|c|c|c|c|}
\hline \multirow{2}{*}{$\begin{array}{c}\text { № } \\
\Pi / \Pi\end{array}$} & \multicolumn{2}{|c|}{ Название вида можжевельника } & \multirow{2}{*}{ Сорт } \\
\hline & русское & латинское & \\
\hline 1 & $\begin{array}{c}\text { Можжевельник } \\
\text { китайский }\end{array}$ & Juniperus chinensis L. & $\begin{array}{c}\text { Kuriwao Gold } \\
\text { Mauntbatten } \\
\text { Monarch } \\
\text { Obelisk } \\
\text { Spartan } \\
\text { Stricta } \\
\text { Variegata }\end{array}$ \\
\hline 2 & $\begin{array}{l}\text { Можжевельник } \\
\text { обыкновенный }\end{array}$ & Juniperus communis L. & $\begin{array}{c}\text { Arnold } \\
\text { Hibernica } \\
\text { Horstman } \\
\text { Meyer } \\
\text { Suesica }\end{array}$ \\
\hline 3 & $\begin{array}{c}\text { Можжевельник } \\
\text { скальный }\end{array}$ & $\begin{array}{l}\text { Juniperus scjpulorum } \\
\text { Sarg. }\end{array}$ & $\begin{array}{c}\text { Blue Arrow } \\
\text { Silver Star } \\
\text { Skyrocket } \\
\text { Wichita Blue }\end{array}$ \\
\hline
\end{tabular}

Таблица 1- Состав коллекции интродуцированных сортов можжевельника с пирамидальной кроной надземной части растений

Исследования зимо- и засухоустойчивости проводились путем оценки надземных частей наблюдаемых видов. Степень зимостойкости и засухоустойчивости определялась по 5-бальной шкале. Средняя зимо- и засухоустойчивость вида определялась в баллах с десятыми их долями как среднее арифметическое из всех баллов при оценке каждого растения.

Степень устойчивости к болезням и вредителям определялась по 5балльной школе путем визуальной оценки повреждений у 10 деревьев каждого вида.

Способность к вегетативному размножению проводили при укоренении черенков в теплице с туманообразующей установкой. Пять баллов получили сорта с укоренение более 80\% черенков, 4 балла - 60- 
70\%; 3 балла - 40-50\%; 2 балла - 20-30\% и 1 балла - менее $20 \%$.

Эстетическую оценку декоративности растений проводили путем подсчета суммы баллов по шкале оценки декоративности, составленной с учетом цифрового выражения однотипной декоративной характеристики. В зависимости от суммы баллов оцениваемые растения подразделялись на категории: высокодекоративные, декоративные, относительно декоративные, малодекоративные, не обладающие декоративными качествами.

Оценка перспективности вида проводилась путем вычисления коэффициента перспективности по следующей шкале:

Группы

Весьма перспективные

Перспективные

Малоперспективные

Неперспективные
Коэффициент перспективности

$0,9-1,0$

$0,8-0,9$

$0,7-0,8$

0,6-0,7

Обсужндение результатов. Вид можжевельника китайского (Juniperus chinensis L.) был представлен в изучении семью сортами. Представлены эти сорта деревьями с колоновидной или пирамидальной кроной. Об этом свидетельствует и ширина кроны растений в 9-летнем возрасте. Все изучаемые сорта имели ширину кроны от 1,2 до 1,9м, а самую широкую крону имели растения сорта Kuriwao Gold (2,1м). Самыми высокорослыми оказались растения сортов Obelisk и Spartan (3,73,8м)(табл. 2)

Эти сорта являются быстрорастущими, и за восемь лет наблюдений ежегодный прирост растений в высоту составил - 33,8-35,0см. Сорта: Monarch, Maunbatten, Variegata имели высоту растений от 2,5 до 2,9м при ежегодном приросте в высоту 18,8-23,8см. Несколько меньшую высоту 2,1м имели растения сорта Stricta, при ежегодном приросте 13,8см. Самым 
низкорослым показал себя сорт Kuriwao Gold - всего 1,1м, а ежегодный прирост составил 7,5см.

Среди изучаемых, имеются сорта, с хвоей различной окраски: зеленой хвоей - Monarch, Obelisk, Spartan, голубовато-зеленой Stricta, голубой

Таблица 2 Биометрические параметры и ежегодный прирост (20082015гг.) надземной части 9-летних растений можжевельника китайского (Juniperus chinensis L.)

\begin{tabular}{|c|c|c|c|c|}
\hline \multirow{2}{*}{ Сорт } & \multicolumn{2}{|c|}{ Высота растений } & \multicolumn{2}{|c|}{ Ширина } \\
\cline { 2 - 5 } & Общая, м & $\begin{array}{c}\text { ежегодный } \\
\text { прирост, см }\end{array}$ & Общая, м & $\begin{array}{c}\text { ежегодный } \\
\text { прирост,см }\end{array}$ \\
\hline Spartan & 3,8 & 35,0 & 1,2 & 10,0 \\
Obelisk & 3,7 & 33,8 & 1,5 & 13,8 \\
Variegata & 2,9 & 23,8 & 1.4 & 12,5 \\
Maunbatten & 2,8 & 22,5 & 1,5 & 17,5 \\
Monarch & 2,5 & 18,8 & 1,9 & 13,8 \\
Stricta & 2,1 & 13,8 & 1,3 & 8,8 \\
Kuriwao Gold & 1,1 & 7,5 & 2,1 & 21,2 \\
\hline HCP05 & 0,2 & 2,0 & 0,2 & 1,3 \\
\hline
\end{tabular}

Maunbatten и пестрой у сортов Variegata и Kuriwao Gold. Такой набор сортов с различными биометрическими параметрами надземной части растений и окраской хвои, желательно использовать для одиночных посадок и садовых композиций, для рокариев и вересковых садов.

В изучении вида можжевельника обыкновенного (Juniperus communis L.) находилось пять сортов. Представлены эти сорта деревьями или кустарниками с формой кроны от коллоновидной до пирамидальной. В 9летнем возрасте самыми высокорослыми оказались растения сортов: Hibernica, Suesica и Meyer, высота которых составила 2,9-3,2м. Эти же 
сорта имеют и самый большой ежегодный прирост растений в высоту 23,827,5см (табл. 3)

Несколько меньшую высоту имели растения сорта Horstman-2,1м и умеренный ежегодный прирост в высоту - 13,8см. Самым низкорослым оказался сорт Arnold - растения высотой не более 1,4м и с годовым приростом в $5,0 \mathrm{~cm}$.

Что касается ширины кроны растений, то у сортов Suesica, Hibernica,

Таблица 3 - Биометрические параметры и ежегодный прирост (20082015гг.) надземной части 9-летних растений можжевельника обыкновенного (Juniperus communis L.)

\begin{tabular}{|c|c|c|c|c|}
\hline \multirow{2}{*}{ Сорт } & \multicolumn{2}{|c|}{ Высота растений } & \multicolumn{2}{|c|}{ Ширина } \\
\cline { 2 - 5 } & Общая, м & $\begin{array}{c}\text { ежегодный } \\
\text { прирост, см }\end{array}$ & Общая, м & $\begin{array}{c}\text { ежегодный } \\
\text { прирост,см }\end{array}$ \\
\hline Meyer & 3,2 & 27,5 & 1,2 & 10,0 \\
Suesica & 3,0 & 25,0 & 1,0 & 7,5 \\
Hibernica & 2,9 & 23,8 & 1,1 & 8,8 \\
Horstman & 2,1 & 13,8 & 1,8 & 17,5 \\
Arnold & 1,4 & 5,0 & 0,3 & 2,5 \\
\hline HСР & 0,2 & 2,1 & 0,2 & 1,2 \\
\hline
\end{tabular}

Meyer она составила 1,0-1.2м, что указывает на колоновидный тип кроны этих растений. У слаборослого сорта Arnold, ширина кроны составила всего лишь 0,3 м, т. е. крона узкоколоновидная. Крона растений сорта Horstman оригинальная раскидистая, при высоте 2,1м, - ширина еe составляет $1,8 \mathrm{M}$.

Среди изучаемых сортов можжевельника обыкновенного встречаются образцы с различной окраской хвои: голубовато-зеленой у сортов - Meyer, Hibernica, Suesica, зелено-серой - Horstman и яркозеленой у сорта Arnold. Такой набор сортов с различными биометрическими параметрами надземной части растений и окраской хвои 
желательно использовать для маленьких приусадебных садов, каменистых и вересковых садов, а также для альпинариев.

Вид можжевельника скального (Juniperus scopulorum Sarg.) в коллекции изучения был представлен четырьмя сортами. Представлены эти сорта растениями с колоновидной или пирамидальной кроной.

В 9 - летнем возрасте, самым высокорослым - 4,0м и быстрорастущим, с ежегодным приростом растений (2008-2015гг) 37,5см. Высоту деревьев в 3,1м имеют растения сорта Blue Arrow при ежегодном приросте в высоту $26,2 \mathrm{~cm}$.

Сорта Silver Star и Wichita Blue имеют высоту растений 2,4-2,5м, при ежегодном приросте 17,5-18,8см. (табл. 4).

Таблица 4 - Биометрические параметры и ежегодный прирост (20082015гг.) надземной части 9-летних растений можжевельника скального (Juniperus scopulorum Sarg.) садов, а также для цветовых растительных композиций и на шпалеры.

\begin{tabular}{|c|c|c|c|c|}
\hline \multirow{2}{*}{ Сорт } & \multicolumn{2}{|c|}{ Высота растений } & \multicolumn{2}{|c|}{ Ширина } \\
\cline { 2 - 5 } & Общая, м & $\begin{array}{c}\text { ежегодный прирост, } \\
\text { см }\end{array}$ & Общая, м & $\begin{array}{r}\text { ежегодный } \\
\text { прирост,см }\end{array}$ \\
\hline Skyrocket & 4,0 & 37,5 & 1,2 & 10,0 \\
Blue Arrow & 3,1 & 26,2 & 1,3 & 11,2 \\
Silver Star & 2,4 & 17,5 & 1,4 & 12,5 \\
Wichita Blue & 2,5 & 18,8 & 1,4 & 12,5 \\
& & & & 1,1 \\
\hline HCP05 & 0,2 & 1,7 & 0,2 & \\
\hline
\end{tabular}

Что касается ширины кроны растений изучаемых сортов, то их размер составил 1,2-1,4м - это свидетельствует об однотипности строения кроны этих сортов. Среди изучаемых, имеются сорта с хвоей различной 
окраски: сине-серой хвоей Skyrocket и Blue Arrow, голубовато-серой хвоей сорт Silver Star и серебристо-синей у сорта Wichita Blue. Данный набор сортов, с различными биометрическими параметрами надземной части растений и окраской хвои, желательно использовать для каменистых садов и небольших приусадебных

При выборе того или иного вида и сорта можжевельника для озеленительных насаждений потребителя интересуют не только биометрические параметры надземной части этих растений, интенсивность роста побегов, но и некоторые другие биологические их особенности.

В процессе многолетнего изучения таких качеств как: зимостойкость, засухоустойчивость, устойчивость к болезням и вредителям, способность к вегетативному размножению и эстетической оценки декоративности, - нам удалось дать оценку перспективности использования интродуцированных можжевельников в озеленении различных объектов в условиях предгорной зоны Краснодарского края. Такая комплексная оценка позволила нам установить для каждого сорта коэффициент и группу перспективности (табл. 5)

Так, все сорта можжевельника китайского, за исключением сортов Variegata и Stricta имеют коэффициент от 1,0 до 0,92 , что позволило отнести их к группе весьма перспективных для использования в озеленении конкретной природно-климатической зоны. Что касается сортов Variegata и Stricta, то коэффициент 0,80 позволил отнести их к группе малоперспективных.

Таблица 5 - Оценка перспективности использования можжевельников в озеленении в годы исследований 2008-2015гг. (по методике Смирнова И.А., 1989) 


\begin{tabular}{|c|c|c|c|c|}
\hline Вид & Сорт & $\begin{array}{l}\text { Сумма } \\
\text { баллов }\end{array}$ & $\begin{array}{c}\text { Коэффициент } \\
\text { перспективнос } \\
\text { ти }\end{array}$ & $\begin{array}{c}\text { Группа } \\
\text { перспективнос } \\
\text { ти }\end{array}$ \\
\hline \multirow{7}{*}{$\begin{array}{c}\text { Можжевельник } \\
\text { китайский }\end{array}$} & Maunbatten & 25,0 & 1,0 & $\mathrm{B \Pi}$ \\
\hline & Obelisk & 24,5 & 0,98 & ВП \\
\hline & Kuriwao Gold & 24,5 & 0,98 & $\mathrm{B \Pi}$ \\
\hline & Spartan & 24,0 & 0,96 & $\mathrm{~B} \Pi$ \\
\hline & Monarch & 23,0 & 0,92 & $\mathrm{BП}$ \\
\hline & Stricta & 20,0 & 0,80 & МП \\
\hline & Variegata & 20,0 & 0,80 & МП \\
\hline \multirow{5}{*}{$\begin{array}{l}\text { Можжевельник } \\
\text { обыкновенный }\end{array}$} & Meyer & 24,0 & 0,96 & ВП \\
\hline & Hibernica & 24,0 & 0,96 & ВП \\
\hline & Suesica & 24,0 & 0,96 & ВП \\
\hline & Horstman & 21,0 & 0,84 & $\Pi$ \\
\hline & Arnold & 20,0 & 0,80 & $\Pi$ \\
\hline \multirow{4}{*}{$\begin{array}{c}\text { Можжевельник } \\
\text { скальный }\end{array}$} & Blue Arrow & 24,0 & 0,96 & $\mathrm{B \Pi}$ \\
\hline & Silver Star & 24,0 & 0,96 & $\mathrm{B \Pi}$ \\
\hline & Skyrocket & 24,0 & 0,96 & ВП \\
\hline & Wichita Blue & 23,0 & 0,92 & ВП \\
\hline
\end{tabular}

Следует учесть, что в период летних засушливых месяцев июльавгуст у данных сортов может отмечаться подгорание хвои и поэтому ухудшается их декоративность.

Сорта можжевельника обыкновенного - Meyer, Hibernica, Suecica получили коэффициент 0,96, что делает эти сорта весьма перспективными для озеленения. Сорта - Horstmann и Arnold получили коэффициенты 0,800,84, что свидетельствует о их перспективности. При использовании сортов и Arnold и Horstmann в озеленении объектов юга России, необходимо 
учесть возможность подгорания хвои этих сортов на фоне повышенной солнечной инсоляции в июле-августе месяце.

Все сорта можжевельника скального за годы исследований получили высокую сумму баллов 23,0-24,0 и коэффициент перспективности 0,920,96. Данные показатели свидетельствуют о высокой перспективности сортов: Blue Arrow, Silver Star, Skyrocket, Wichita Blue для использования в озеленении различных объектов предгорной зоны Краснодарского края.

Таким образом, анализ полученных многолетних экспериментальных данных биометрических параметров роста и комплексной оценки перспективности 16 сортов можжевельника позволяет нам сделать следующие выводы и рекомендации по использованию их в озеленительных насаждениях предгорной зоны Краснодарского края.

1. Из семи сортов можжевельника китайского - пять отнесены к весьма перспективным, а сорта Variegata и Stricta к малоперспективным. Учитывая биометрические параметры надземной части растений сортов этого вида, следует использовать их для одиночных посадок и садовых композиций, для рокариев и вересковых садов.

2. Из пяти сортов можжевельника обыкновенного к группе весьма перспективных отнесены - Meyer, Hibernica, Suecica. Перспективными следует считать сорта - Arnold и Horstmann. Биометрические параметры надземной части растений сортов: Meyer, Hibernica, Suecica позволяют рекомендовать их для небольших приусадебных и вересковых садов. Слаборослый сорт Arnold приемлем для альпинариев, a copт Horstmann следует высаживать одиночно на газонах.

3. По итогам изучения, все сорта можжевельника скального отнесены к весьма перспективным. С учетом силы роста растений, данные сорта следует использовать для каменистых садов, а также для цветовых растительных композиций и на шпалеры. 


\section{Литература}

1. Шевырева Н. Хвойные растения. Большая энциклопедия/ Н. Шевырева, Т. Коновалова. - м. : Эксмо,2012. - 280с.

2. Кучинская Е.А.Эколого-биологические особенности голосеменных интродуцентов Адыгеи // Известия ВУЗов Северо-Кавказский регион. Естественные науки.- Ростов-на-Дону: РГУ, 2006

3. Седина Ю.В. Интродукция видов, рода Juniperus в Западной предгорной зоне Краснодарского края / Ю.В. Седина

4. Проворченко А.В. Эффективность производства посадочного материала можжевельников в зависимости от вида исходного материала / А.В. Проворченко, С.Н. Бирюков, Ю.В. Седина, О.А. Проворченко // Политематический сетевой электронный научный журнал Кубанского аграрного университета. 2013. №93 (09).

5. Программа и методика сортоизучения плодовых, ягодных и орехоплодных культур. - Орел, 1999. - 606с.

6. Смирнов И.А. Методика определения перспективности интродукции древесных растений / И.А. Смирнов. - Майкоп, 1989.

\section{References}

1. Shevyreva N. Hvojnye rastenija. Bol'shaja jenciklopedija/ N. Shevyreva, T. Konovalova. - m. : Jeksmo,2012. - 280s.

2. Kuchinskaja E.A.Jekologo-biologicheskie osobennosti golosemennyh introducentov Adygei // Izvestija VUZov Severo-Kavkazskij region. Estestvennye nauki.Rostov-na-Donu: RGU, 2006

3. Sedina Ju.V. Introdukcija vidov, roda Juniperus v Zapadnoj predgornoj zone Krasnodarskogo kraja / Ju.V. Sedina

4. Provorchenko A.V. Jeffektivnost' proizvodstva posadochnogo materiala mozhzhevel'nikov v zavisimosti ot vida ishodnogo materiala / A.V. Provorchenko, S.N. Birjukov, Ju.V. Sedina, O.A. Provorchenko // Politematicheskij setevoj jelektronnyj nauchnyj zhurnal Kubanskogo agrarnogo universiteta. 2013. №93 (09).

5. Programma i metodika sortoizuchenija plodovyh, jagodnyh i orehoplodnyh kul'tur. - Orel, 1999. - 606s.

6. Smirnov I.A. Metodika opredelenija perspektivnosti introdukcii drevesnyh rastenij / I.A. Smirnov. - Majkop, 1989. 